\title{
EXPERIMENTAL STUDIES OF IMPACT OF EXHAUST GAS RECIRCULATION ON THE EFFECTIVE OPERATION IN HEAVY AUGMENTED DIESEL ENGINE
}

\author{
V. M. Gureev, A. Kh. Khayrullin, R. R. Khasanov, M. V. Gureev, R. R. Salakhov, F. A. \\ Varlamov
}

Kazan National Research Technical University named after A. N. Tupolev

Published online: 15 February 2017

\begin{abstract}
This paper considers the problem of reducing the nitrogen oxides emissions in exhaust gases (EG) of diesel engine by exhaust gas recirculation (EGR). Based on the carried out study the influence of EGR on technical-and-economic and environmental performance of a diesel engine was found as well as main directions of improving a working process of diesel engines with EGR system were formulated.
\end{abstract}

Keywords: diesel engine, warm-up mode, exhaust toxicity, exhaust gas recirculation, nitrogen oxides $\left(\mathrm{NO}_{\mathrm{x}}\right)$, heat exchanger of system exhaust gas recirculation.

\section{INTRODUCTION}

The problem of increase the efficiency and operational reliability of the internal combustion engine (ICE) is a priority subject for the engine design in the coming decades in accordance with the requirements of environmental law. An extreme increase commercial and passenger vehicles equipped with the ICE leads to a periodic tightening of regulatory restrictions to emissions. Therefore, the main stream in the ICE studies is given by the requirements to the exhaust emissions. These requirements and consumer demands for fuel economy as well initiate the research activities in area of ICE design. It should be noted that a problem of efficiency increasing and a problem of concentration reducing for toxic components of the EG (nitrogen oxides (NOx), hydrocarbons ( ), carbon monoxide ( ) and dispersed particles $\mathrm{Pt}$ ) in accordance with the rules №24 and 49 of the ECE UN are contradictory.

Author Correspondence, e-mail: author@gmail.com

doi: http://dx.doi.org/10.4314/jfas.v9i1s.682 
The complexity of solving this problem lies in the fact that the transport engine exploited in wide range of load and rotation speed. Usually, the terms of reducing emissions $\mathrm{NOx}, \mathrm{CH}$ and Pt in the exhaust gas and specific fuel consumption BSFC are opposite. Traditional methods of the emission control, such as changing settings of the fuel injection system (for example, reducing the angle of the fuel with simultaneous increase of fuel feeding pressure) allows to move to a higher environmental level of emissions of normalized components, but it reduces fuel economy or require the installation of additional systems for exhaust emission neutralization (catalysts, particle filters, EGR system, etc.), which in turn requires additional work to adapt these systems to the operation conditions of the engine.

Traditional approach of reducing EG toxicity is to change the fuel-injection equipment (FIE) settings. Reducing the onset angel of fuel supply allows passing to a higher environmental level on emissions of normalized components but it reduces fuel efficiency. Alternatively, it is necessary to install additional purification and neutralization systems (catalysts, particulate filters, EGR system and etc.) it, in turn, requires additional finishing work on the adaptation of these systems with engine operation.

Regularity of influence of EGR on behavior of intra cylinder processes in ICE lies in reducing the maximum temperature in the cylinder combustion zones by adding the inert gases $\left(\mathrm{CO}_{2}\right.$ and $\mathrm{N}_{2}$ ) to the air supplied in the cylinder [1,2].

Study goal is to evaluate the influence of EGR on technical-and-economic and environmental performance of high-uprated diesel engine under conditions of engine test bench. The studies were carried out at the regimes $n=1250 ; 1500$ and $1750 \mathrm{rpm}$ at a load 25;50; 75 and $100 \%$. Recycle rate $\gamma$ was calculated by the formula

$$
\gamma=100 \cdot \mathrm{CO}_{2 \_ \text {inl }} / \mathrm{CO}_{2 \_ \text {exh }},
$$

where $\mathrm{CO}_{2}$ inl $-\%$ of carbon dioxide according to measurements in the inlet manifold after charge air cooler; $\mathrm{CO}_{2 \_ \text {ehx }}-\%$ of carbon dioxide according to the measurements in EG.

The study subject is a reciprocating four-stroke eight-cylinder $\mathrm{V}$ diesel with working volume $\mathrm{iV}_{\mathrm{h}}=11.76 \mathrm{1}$, piston stroke $\mathrm{S}=130 \mathrm{~mm}$, cylinder diameter $\mathrm{D}=120 \mathrm{~mm}$, equipped with turbocharging, aftercooling and accumulator system of fuel supply of «Common Rail» type and a rated power $N_{\mathrm{e}}=338.5 \mathrm{~kW}$ at crankshaft speed $n=1900 \mathrm{rpm}$.

Fig.1 demonstrates different constructive schemes of the EGR system installed on the test engine. 


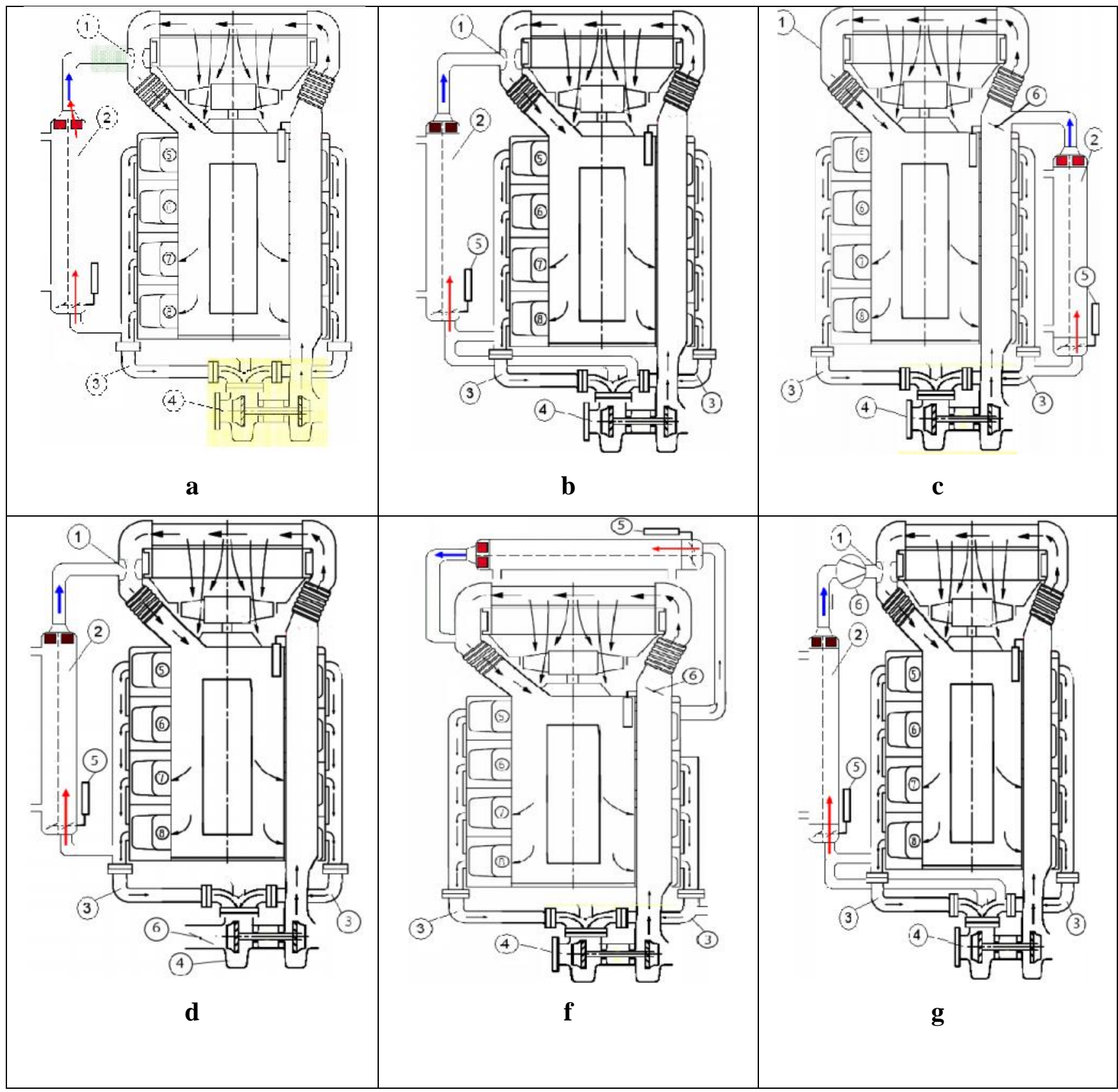

Fig 1. Schemes of EGR system for configuration of test engine

1-mixer; 2-heat exchanger; 3-exhaust manifold; 4-turbocharger; 5-valve ; 6-throttle valve on $\mathrm{c}, \mathrm{d}, \mathrm{f}$ and compression on $\mathrm{g}$

Fig. 1a shows structural scheme of EGR system on the engine under study. This scheme is optimal with regard to layout and simplicity of alternate design. In the selected scheme bleeding of EG was carried out from right exhaust manifold and subsequent cooling in a heat exchanger. The EG supply in the inlet manifold was carried out after charge air cooler using a special mixer. The coolant fed to the heat exchanger of the internal circuit of the engine cooling system, and the heated water is sent back into the cooling system (fig. 2). The main 
advantage of the chosen design solution is the possibility of a more rapid warming of the coolant in the cooling system of the engine warm-up mode, which in turn will allow for faster go to a more economical engine operation and to ensure efficient operation of heating, ventilation and air-conditioning the cabin interior. It should be noted that this is a problem for vehicles operated in different climatic zones.

During the experimental studies in this case the coolant temperature was $80-85^{\circ} \mathrm{C}$.

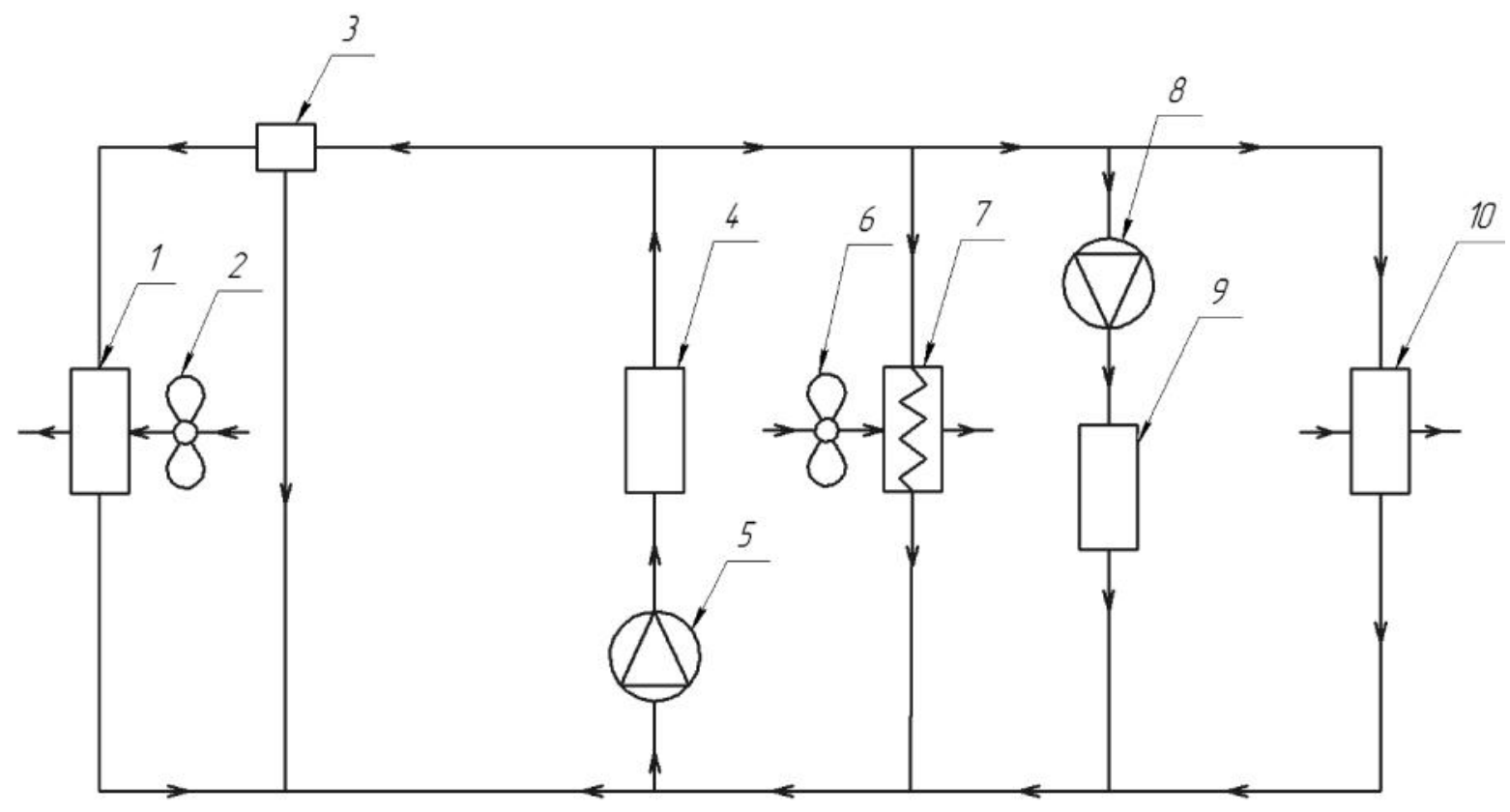

Fig. 2. Hydraulic scheme of the engine cooling system and heating the vehicle cabin

1 - heat exchanger of engine cooling system; 2 - fan of engine cooling system; 3 -

thermostat; 4 - internal combustion engine; 5 - pump of engine cooling system;

6 - fan of air conditioner; 7 - heat exchanger of air conditioner; 8 - pump of auxiliary heat exchanger of cabin interior; 9 - auxiliary heat exchanger of cabin interior; 10 - heat exchanger of exhaust gas recirculation.

Table 1 presents the characteristics of EGR system and its influence on the pressure and temperature in the inlet $P_{\mathrm{s}}, T s$ and exhaust $P_{\mathrm{t}}, T t$ manifolds at the studied regimes. Application of EGR led to a reduction of the engine air flow because of the decreasing pressure and increasing temperature $T_{\mathrm{s}}$ of the air in the inlet manifold. Also it should be noted that EG temperature $T_{\mathrm{t}}$ slightly increases before a turbine but in this case EG pressure significantly decreases from 5.7 to $17.5 \%$. High efficiency of EGR heat exchanger (E) on all regimes and low EG recycle rate that significantly decreases with an increase of load should be noted. Analysis of the obtained data showed that maximum value of EGR rate is reached on all regimes at $25 \%$ load and is in the range $10-14 \%$ since at this load $P_{\mathrm{t}} / P_{\mathrm{s}}$ ratio has a 
maximum value which, in turn, is a determining factor of $\gamma$ value in the EGR system design under study. The high degree of EGR on engine operating conditions at low loads will reduce the time it takes to warm up the coolant.

Table 1.Characteristics of the EGR system and a change of temperature and pressure in the inlet and exhaust manifolds on regimes of ESC cycle

\begin{tabular}{|c|c|c|c|c|c|c|c|}
\hline \multirow{2}{*}{ Load } & $\begin{array}{c}\text { Crankshaft } \\
\text { speed }\end{array}$ & $\mathrm{E}$ & $\mathrm{R}$ & $T \mathrm{~s}$ & $P \mathrm{~s}$ & $P \mathrm{t}$ & $T \mathrm{t}$ \\
\hline \multirow{3}{*}{25} & $\mathrm{rpm}$ & \multicolumn{2}{|c|}{$\sigma, \%$} & \multicolumn{4}{|c|}{$\delta, \%$} \\
\cline { 2 - 9 } & 1250 & 100,00 & 10,60 & 3,40 & 10,50 & 12,50 & $-3,90$ \\
\cline { 2 - 9 } & 1500 & 99,20 & 10,00 & 2,10 & 12,10 & 14,30 & $-4,20$ \\
\hline \multirow{3}{*}{50} & 1750 & 98,30 & 12,20 & 1,20 & 11,50 & 17,50 & $-3,60$ \\
\cline { 2 - 9 } & 1250 & 100,00 & 4,30 & 3,40 & 6,00 & 9,30 & $-4,00$ \\
\cline { 2 - 9 } & 1500 & 99,40 & 6,80 & 1,80 & 8,00 & 12,00 & $-4,20$ \\
\hline \multirow{3}{*}{75} & 1750 & 98,10 & 8,30 & 0,50 & 6,00 & 13,50 & $-2,40$ \\
\cline { 2 - 9 } & 1250 & 100,00 & 3,10 & 0,70 & 3,50 & 5,70 & $-3,40$ \\
\cline { 2 - 9 } & 1750 & 99,30 & 5,10 & 1,50 & 5,40 & 10,30 & $-3,10$ \\
\hline \multirow{3}{*}{100} & 1250 & 100,00 & 2,50 & $-1,10$ & 2,50 & 5,20 & $-3,40$ \\
\cline { 2 - 8 } & 1500 & 99,10 & 4,50 & 0,80 & 2,90 & 9,10 & $-2,00$ \\
\cline { 2 - 8 } & 1750 & 97,10 & 7,10 & 2,70 & 0,00 & 10,40 & 0,50 \\
\hline
\end{tabular}

Fig.3 shows the dependencies of $\gamma$ and $P_{\mathrm{t}} / P_{\mathrm{s}}$ ratios related to the value of engine load at $n=$ 1250, 1500 and $1750 \mathrm{rpm}$. 


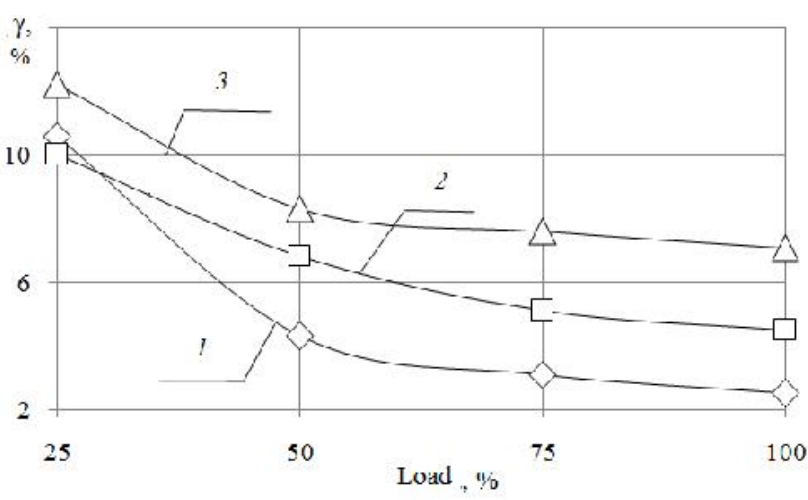

$a$

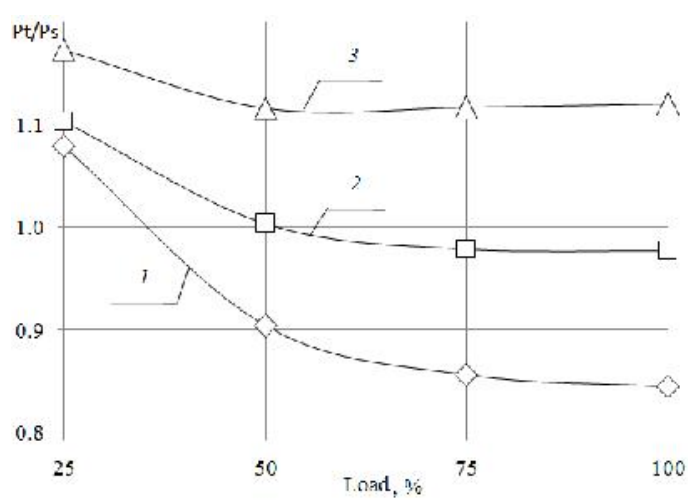

$b$

Fig. 3. Dependence of EGR rate and $P_{\mathrm{t}} / P_{\mathrm{s}}$ ratio when engine operates on regimes of ESC cycle:

$$
1-1250 \mathrm{rpm}^{1} ; 2-1500 \mathrm{rpm} ; 3 \text { - } 1750 \mathrm{rpm}
$$

Fig. 4 shows the influence results of EGR on specific effective flow rate of fuel $g_{e}$ and engine air mass flow $G_{\text {air }}$ coming from compressor stage of the turbocompressor according to the load characteristics at crankshaft speed 1250, 1500 and $1750 \mathrm{rpm}$. It should be noted that application of EGR led to a slight change in fuel economy at a load of $25 \%$ at all studied crankshaft speeds and at $n=1250 \mathrm{rpm}$ value of specific effective flow rate of fuel decreased by $1 \%$. Increase of load from 50 to $100 \%$ resulted in a decrease of the engine fuel efficiency at $n=1250 \mathrm{rpm}$ from 1 to $2.7 \%$, at $n=1500 \mathrm{rpm}$ increase did not exceed $0.5 \%$ and at $n=$ $1750 \mathrm{rpm}$ decrease from 0.2 to $0.5 \%$ (fig. 5, a). Engine air mass flow reduced at decrease of load on all studied frequencies by $4-13 \%$ depending on the regime. The resulting dependence of $G_{\text {air }}$ reduction versus load is caused by the increase of $\gamma$ value with a decrease of load that, in turn, influences on the turbocompressor working regime, pressure and temperature of the air in the inlet manifold (fig. 5, $b$ ) 


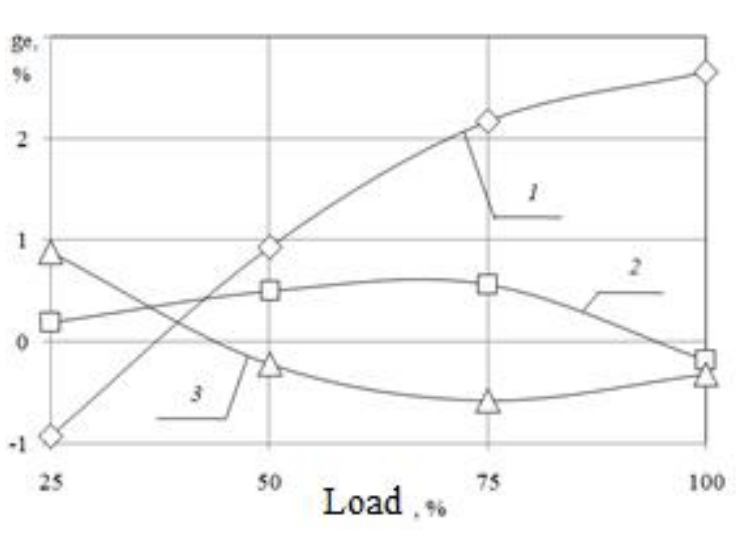

$a$

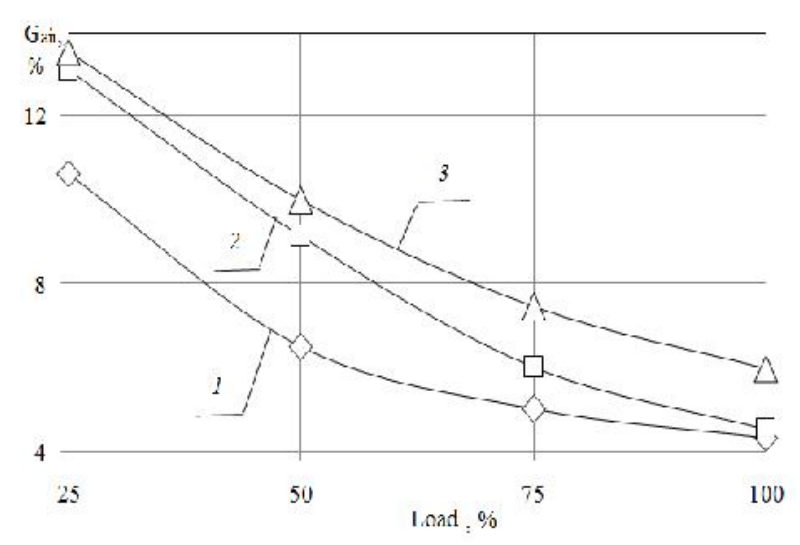

$b$

Fig. 4. Influence of EGR when operating on regimes of ESC cycle:

1 - $1250 \mathrm{rpm} ; 2$ - $1500 \mathrm{rpm} ; 3$ - $1750 \mathrm{rpm}$; Load, \%

- specific effective fuel flow rate $\mathrm{g}_{\mathrm{e}} ; b$ - engine air flow Gair coming from

turbocompressor.

Fig. 4 presents results of reducing $\mathrm{NO}_{\mathrm{x}}$ concentration in $\mathrm{EG}$ when diesel engine operates with EGR system under load at crankshaft speeds $n 1250 ; 1500$ and $1750 \mathrm{rpm}$. It is seen from the analysis that the intensity of decreasing $\mathrm{NO}_{\mathrm{x}}$ concentration in $\mathrm{EG}$ increases with higher crankshaft speed to a greater degree at medium and high loads.

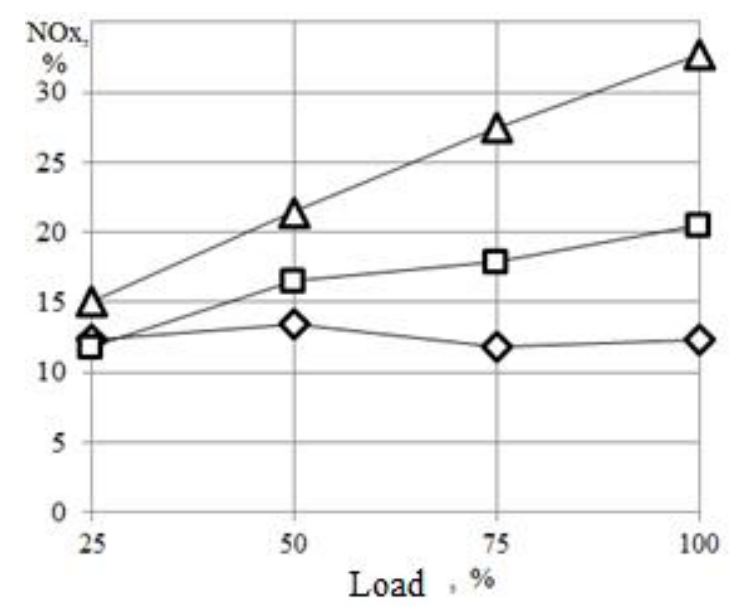

Fig. 5. Reduction of NOx concentration when applying EGR on the regimes: 1 - $1250 \mathrm{rpm} ; 2$ - $1500 \mathrm{rpm} ; 3$ - $1750 \mathrm{rpm}$.

The results obtained when engine was operating according to altitude-speed performances show that applying EGR leads to increase of $g_{\mathrm{e}}$ from 2 to $17 \mathrm{~g} /(\mathrm{kW} \cdot \mathrm{h})$ at a crankshaft speed in 
the range $900-1700 \mathrm{rpm}$ and to decrease from 1 to $3.5 \mathrm{~g} /(\mathrm{kW} \cdot \mathrm{h})$ with increasing crankshaft speed from 1700 to $1900 \mathrm{rpm}$ (fig. 6, a). EGR influence on $\mathrm{NO}_{\mathrm{x}}$ concentration in EG when engine operates according to altitude-speed performances is shown in fig. $6, b$.
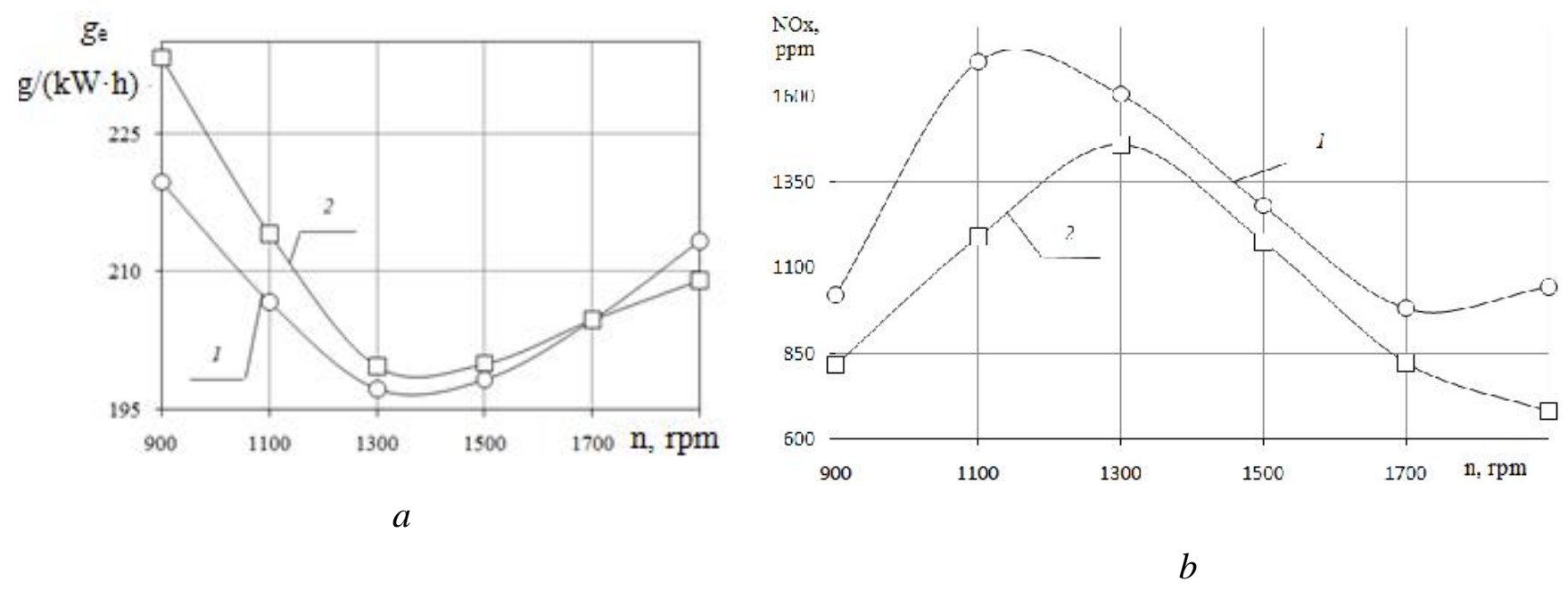

Fig.6. EGR influence when engine operates according to altitude-speed performances:

1 - without EGR system; 2 - with EGR system; n, rpm ge, g/(kW·h)

$a-$ specific effective fuel flow rate $\mathrm{g}_{\mathrm{e}} ; b-\mathrm{NO}_{\mathrm{x}}$ concentration in $\mathrm{EG}$.

\section{CONCLUSIONS}

Analysis of the study results in general showed the presence of EGR influence on $\mathrm{NO}_{\mathrm{x}}$ concentration in EG and fuel efficiency of high-uprated diesel engine. Application of EGR system allowed reducing the $\mathrm{NO}_{\mathrm{x}}$ emissions by $10-35 \%$ on the studied regimes.

2. In order to improve effective and environmental performance of the studied diesel engine it is necessary to carry out further research in the following directions:

- adjustment of fuel-injection equipment (maximum pressure of fuel supply, number of stages, proportion of fuel in each portion, fuel supply angle and angular interval between stages);

- selection of turbocompressor (determination of optimal characteristics of compressor and turbine wheels) and methods for its adjustment.

3. Hydraulic cooling scheme of the engine and the heating of the vehicle cabin researched in this work will significantly reduce the time required to warm up the engine and cabin interior. This work was financially supported by the Ministry of Education and Science of the Russian Federation (the unique identifier of the agreement - RFMEFI57715X0195) 


\section{REFERENCES}

1. Semenov B.N., Smaylis V.I., Bykov V.Yu., Lipchuk V.A. Possibilities to reduce the nitrogen oxides emissions with exhaust gases of high-speed uprated diesel engine while maintaining high fuel efficiency // DVIGATELESTROYENIYE. - 1986. - No. 9. - pp. 3 - 6. 2. Smaylis V.I. Current status and new environmental problems of diesel engine manufacturing // DVIGATELESTROYENIYE. - 1991. - No. 1, - pp. 3 - 6.

\section{How to cite this article:}

Gureev M V, Khayrullin A Kh, Khasanov R R, Gureev M V, Salakhov S R, Varlamov F A. Experimental studies of impact of exhaust gas recirculation on the effective operation in heavy augmented diesel engine. J. Fundam. Appl. Sci., 2016, 9(1S), 122-130. 